\title{
LASER MACHINING OF MELT INFILTRATED CERAMIC MATRIX COMPOSITE
}

Jarmon, D. C. ${ }^{1}$, Ojard, G. ${ }^{2}$, and Brewer, D. ${ }^{3}$

${ }^{1}$ United Technologies Research Center, East Hartford, CT

${ }^{2}$ Pratt \& Whitney, East Hartford, CT

${ }^{3}$ NASA - Langley Research Center, Hampton, VA

\section{ABSTRACT}

As interest grows in considering the use of ceramic matrix composites for critical components, the effects of different machining techniques, and the resulting machined surfaces, on strength need to be understood. This work presents the characterization of a Melt Infiltrated $\mathrm{SiC} / \mathrm{SiC}$ composite material system machined by different methods. While a range of machining approaches were initially considered, only diamond grinding and laser machining were investigated on a series of tensile coupons. The coupons were tested for residual tensile strength, after a stressed steam exposure cycle. The data clearly differentiated the laser machined coupons as having better capability for the samples tested. These results, along with micro-structural characterization, will be presented.

\section{INTRODUCTION}

There is ever increasing interest in Ceramic Matrix Composites (CMCs) for multiple high temperature applications [1,2]. This is shown by the interest in CMCs for gas turbine engines for turbine and combustor applications $[3,4]$. The reason for this interest is the high temperature capability of CMCs with increased damage tolerance present from the high strength fibers and weak fiber interface of the composite [2]. Extensive work is ongoing to characterize CMCs for various insertion opportunities. As for any material, part of the consideration for the use or insertion of the material is the machining. This is especially true for CMCs because the machining method and machining parameters can significantly affect the performance. As would be expected for a CMC material, machining would initially start with diamond grinding, since this was a standard procedure for monolithic ceramic materials. The American Society for Testing and Materials (ASTM) standards exist for testing of ceramic materials which include detailed machining procedures [5]. The ASTM machining procedures are used extensively for CMC materials and can be done either dry or wet (coolant). There may be some concerns about coolant use and its effect on the weak interface.

With this background, different machining approaches were considered for the Melt Infiltration (MI) SiC/SiC system including: water jet, electrical discharge, and laser machining. Electrical discharge could be considered because of the presence of the conductive , metallic Si alloy phase in the MI SiC/SiC system. Laser machining was chosen due to the fact that no liquid medium was required. This eliminated any concerns about liquid effects on the weak interface. A series of samples were machined with both diamond grinding and laser machining. These samples were then tested in a steam environment under load for 100 hours. After exposure, residual properties and micro-structural characterization was performed. The results of this work will be presented. 


\section{PROCEDURE}

Material

The material used for this study was the Melt Infiltrated SiC/SiC CMC system as noted previously. This material has been studied extensively [6,7]. The material consists of a stochiometric SiC fiber in a complex sequenced matrix. The Sylramic ${ }^{\circledR}$ fiber was fabricated by DuPont as a $10 \mu \mathrm{m}$ diameter stochiometric SiC fiber and bundled into tows consisting of 800 fibers. The sizing applied was polyvinyl alcohol (PVA). The tow spools were then woven into a 5 harness satin (HS) balanced weave at 18 per inch (EPI). This resulted in 36\% volume fraction of fibers. The fabric was then laid in graphite tooling to correspond to the final part design (flat plates for this experimental program). All the panels were manufactured from a symmetric cross ply laminate using a total of 8 plies. The graphite tooling has holes to allow the CVI deposition to occur. In the first CVI phase, the BN layer was applied to provide the weak interface $(0.5$ microns thick). This was followed by $\mathrm{SiC}$ vapor deposition around the tows. Typically, densification is done to about $30 \%$ open porosity. SiC particulates are then slurry cast into the material followed by melt infiltration of a Si alloy to arrive at a nearly full density material. The material at this time has less than $2 \%$ open porosity. Typical cross sections of this material are shown in other work by the authors [8]. The predominance of the Si phase is shown in Figure 1.

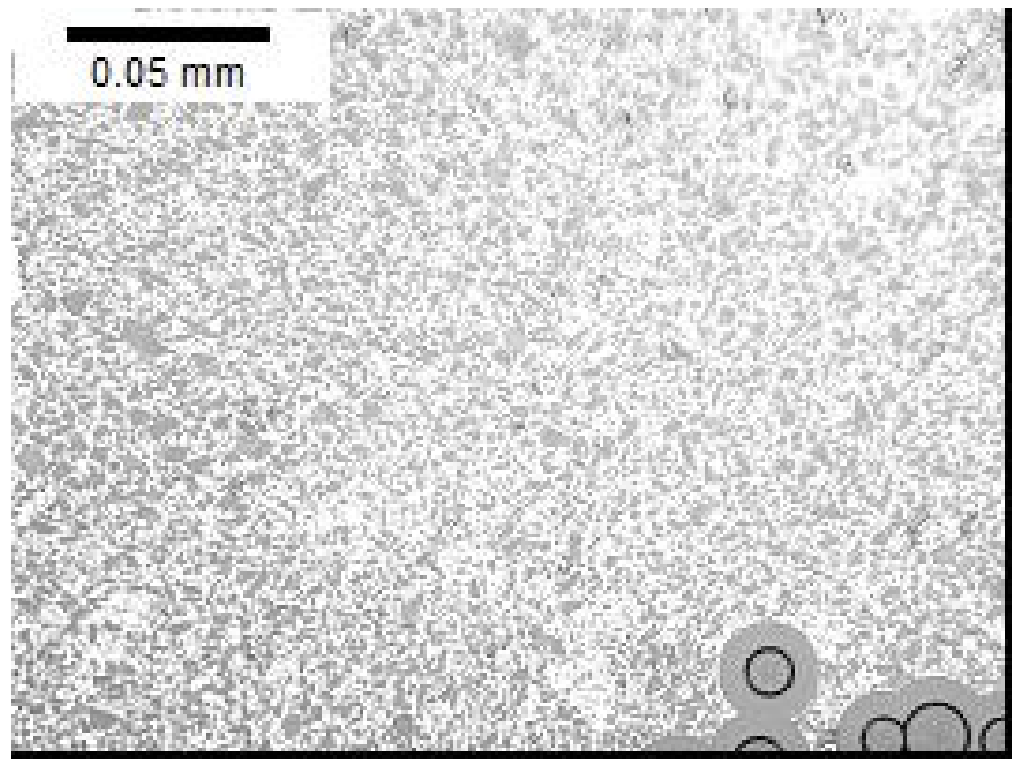

Figure 1. Optical Image showing Silicon Matrix Phase (white) with SiC Particulates (grey). SiC fiber coated with CVI SiC in lower right corner

Machining

Diamond Grinding:

The baseline for the diamond grinding data was from the existing material database as noted previously [6,7]. For this effort, there were two vendors used who nominally use the same process. The material to be machined was mounted to a fixture plate using a low temperature bonding adhesive [5]. The sample was then blanked using a slitting wheel attached to the 
grinding machine. Final touch up on the edges was performed with a standard surface grinder using a 320 grit resin bonded wheel. A synthetic water based coolant was used for the slitting and grinding steps [5]. After these steps the sample was available for testing and no further machining or polishing was done.

\section{Laser Machining:}

The laser machining for this effort was done using a pulsed YAG (Yttrium, Aluminum, Garnet) laser with conditions based on experience arrived at by United Technologies Research Center (UTRC) [9]. For this effort, the linear cutting rate was set at $7.6 \mathrm{~mm} / \mathrm{min}(0.3 \mathrm{in} / \mathrm{min})$. It was determined that the laser can punch through the material (peck time) in 3 seconds. As the laser moved through the material, it removed $0.13 \mathrm{~mm}(0.005 \mathrm{in})$ of material, which is at least one third of the kerf for diamond slicing. $\mathrm{A} \mathrm{CO}_{2}$ laser was not considered for this effort. It was learned that this type of laser can heat the CMC material substantially, resulting in melting or causing reactions in ceramic materials.

Characterization/Exposure/Testing:

After the machining processes were performed, a series of characterization efforts were undertaken. Standard micro-structural characterization was done on the machined samples: optical and scanning electron microscopy (SEM). In addition, a series of dwell-fatigue tests were performed on the samples in a $90 \%$ relative humidity environment. The dwell fatigue test was a modified creep test that was performed at an elevated temperature of $815^{\circ} \mathrm{C}\left(1500^{\circ} \mathrm{F}\right)$. The load was cycled on and off every two hours in order to break down any protective oxides that would form in cracks resulting from the testing [2]. For this testing, there were 4 samples from the diamond grinding (two vendors) and laser machining. (This resulted in 8 samples being diamond ground and 4 samples being laser machined. There is no effort in this paper to differentiate between the two diamond grinding vendors.) The stress level for the testing was set at $117.3 \mathrm{MPa}(17 \mathrm{ksi})$. This level is below the offset proportional limit but above the microcracking stress of the material [10]. The run-out time for this series of tests was set at 100 hours. If the samples did not fail, residual tensile tests were to be done at room temperature.

\section{RESULTS}

\section{Optical Cross Sections (Pre Test)}

Optical cross sections from the different machining approaches are shown in Figures 2 and 3. Figure 2 is representative of images from the diamond grinding effort. The images from the diamond grinding approach show cracking, possibly a result from the machining effort. The severity of the cracking, shown in Figure 2, was not seen for the full breadth of the diamond ground specimen, but minor cracking was seen in all the images taken. The optical microstructure from the laser machined specimen is shown in Figure 3. Cracking is still observed, but it does not extend as far into the material as was the case for the diamond grinding. A distinct difference can be seen in the laser machining effort as a re-cast layer formed on the surface. It is clear that this resulting layer is not uniform, but was present at all machined surfaces. The recast layer formed such that any cracks formed (as shown in Figure 3) were not surface breaking (as was seen in Figure 2 for the diamond ground samples). 


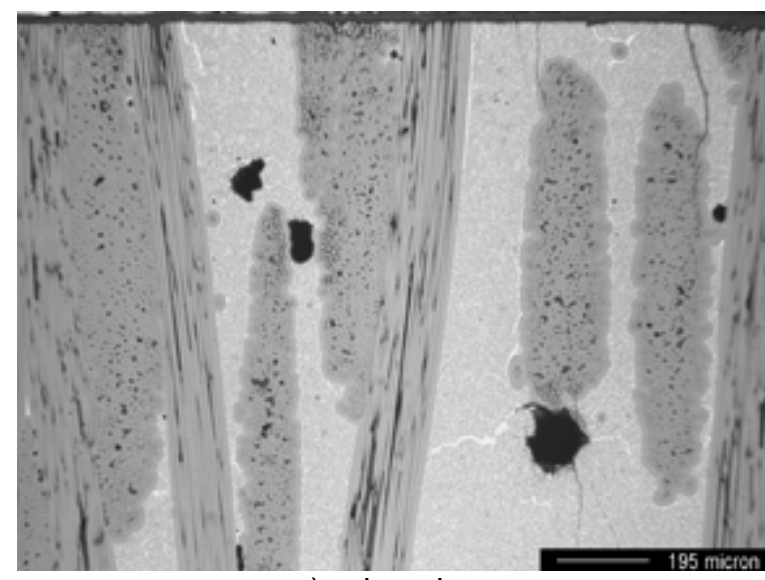

a) edge view

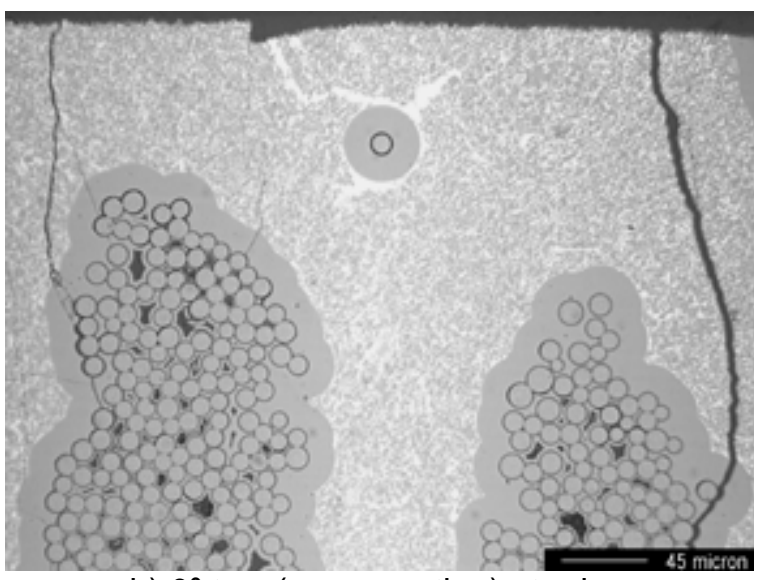

b) $0^{\circ}$ tow (cross section) at edge

Figure 2. Optical Cross Section from Sample that was machined by Diamond Grinding

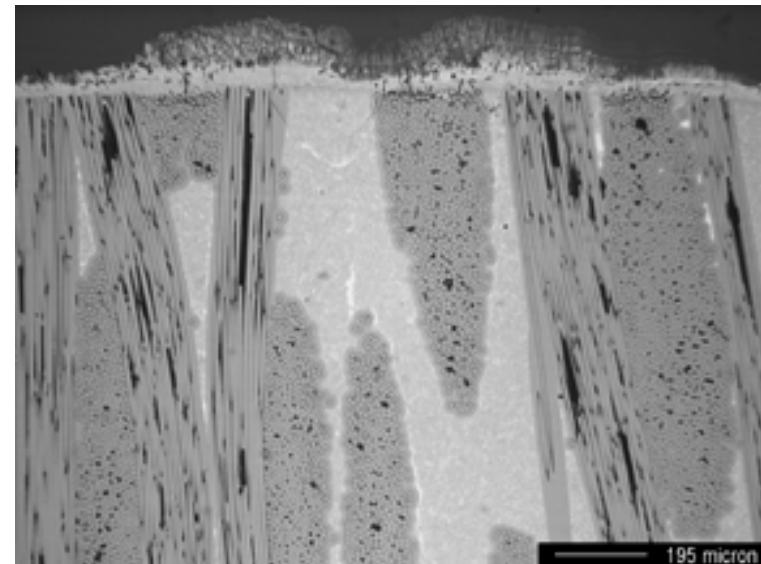

a) edge view

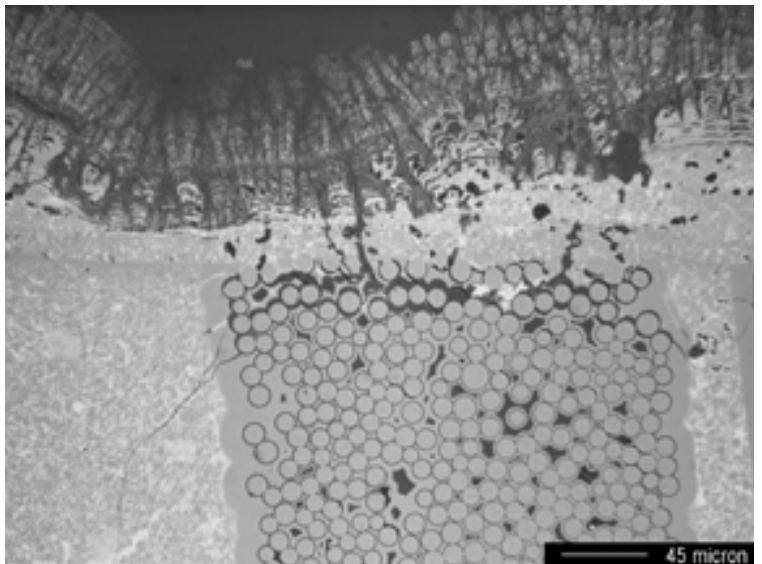

b) $0^{\circ}$ tow (cross section) at edge

Figure 3. Optical Cross Section from Sample that was machined by Laser

\section{Exposure (Steam)}

The 12 samples machined for this effort were all tested in a 2-hour dwell fatigue test at $815^{\circ} \mathrm{C}$ $\left(1500^{\circ} \mathrm{F}\right)$. This testing was not done in air, but the rig was modified to allow the chamber to hold a steam environment of $90 \%$ relative humidity. As was noted, the run-out time for this testing was set at 100 hours. All 12 samples achieved the run-out time of 100 hours. There were no failures of the samples. All samples were subsequently tensile tested at room temperature to determine their residual properties.

\section{Tensile Testing - Residual Properties}

Room temperature tensile testing was performed on the 12 samples after steam exposure. The average results of this testing are shown in Table I. Table I shows that there was no difference in the in-plane tensile modulus between the two machining methods. The laser machining shows a higher strength and strain to failure. This is also shown in the select stress-strain curves, shown in Figure 4. The average material Ultimate Tensile Strength (UTS), from diamond ground specimens without exposure, was $336 \mathrm{MPa}$, with a corresponding strain to failure of 0.0038 $\mathrm{mm} / \mathrm{mm}[6,7]$. And a corresponding modulus of $273 \mathrm{GPa}$. It is clear that the exposure (under load and steam) had reduced the material strength and strain to failure, but to differing extent depending on the machining approach. 
Table I. Average Room Temperature Residual Tensile Test Results

\begin{tabular}{|l|c|c|c|c|}
\hline Machining Method & Analysis & Modulus & UTS & Strain to Failure \\
\hline & & $(\mathrm{GPa})$ & $(\mathrm{MPa})$ & $(\mathrm{mm} / \mathrm{mm})$ \\
\hline & & & & 188.7 \\
\hline & Average & 254.2 & 23.66 & 0.00095 \\
\hline & StDev & 28.32 & 23.000143 \\
\hline Laser Machining & & & & 0.00196 \\
\hline & Average & 258.6 & 270.2 & 0.000103 \\
\hline
\end{tabular}

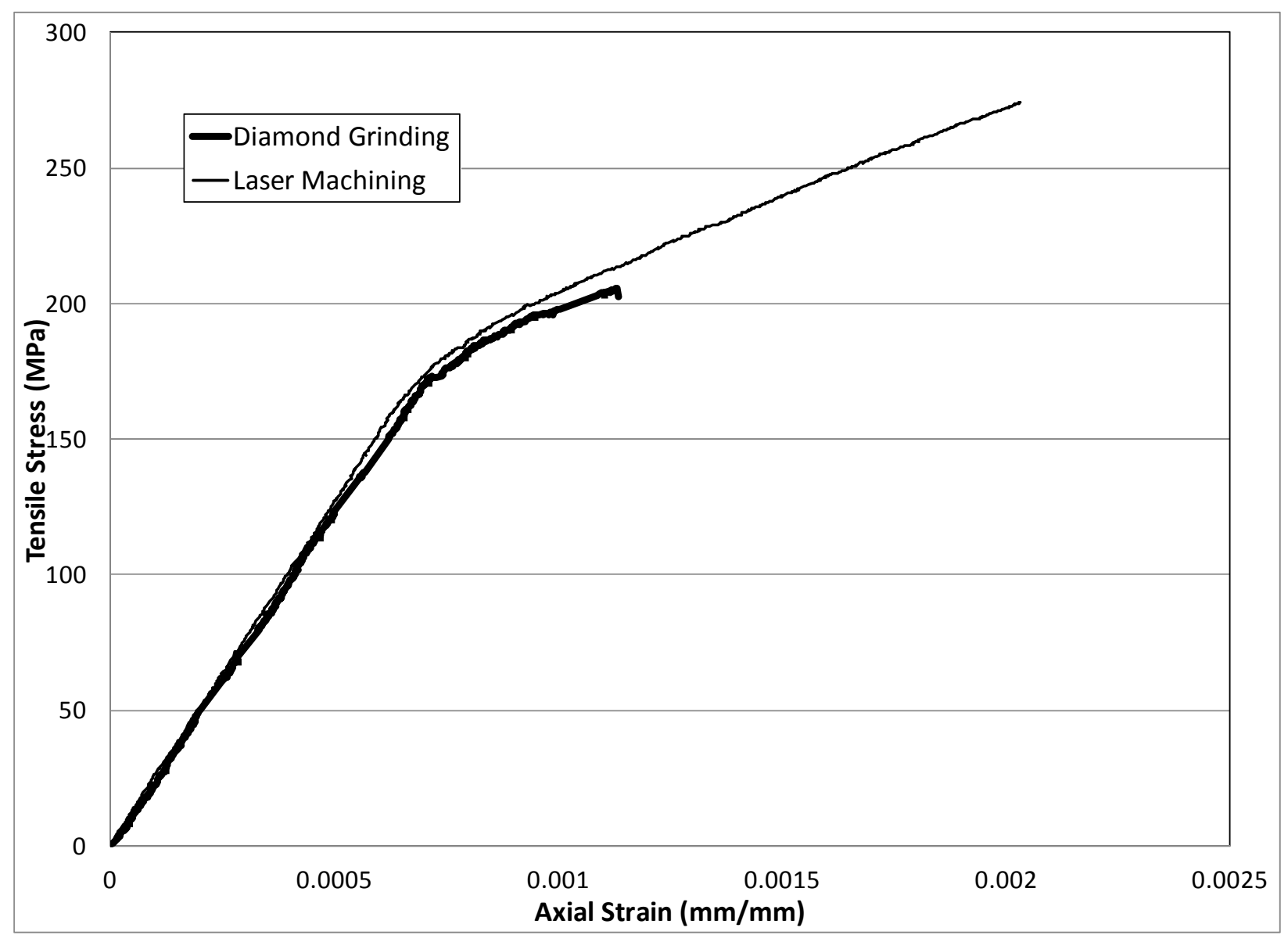

Figure 4. Select Residual Tensile Stress-Strain Curves

SEM Failure Face Analysis (Post Exposure and Residual Testing)

In order to gain additional insight into the residual stress-strain behavior, failed tensile bars were interrogated in an SEM. Figures 5 and 6 show images of samples from the different machining methods used. Figure 5 shows that there is very little fiber pullout present between the two methods and this was consistent with the low strain to failure. Higher magnification work was done (See Figure 6) and the images taken from the diamond grinding effort show that 
the interface has been oxidized away. The interface coating for the laser machining effort was not as affected and was consistent with the slightly higher strain to failure observed.

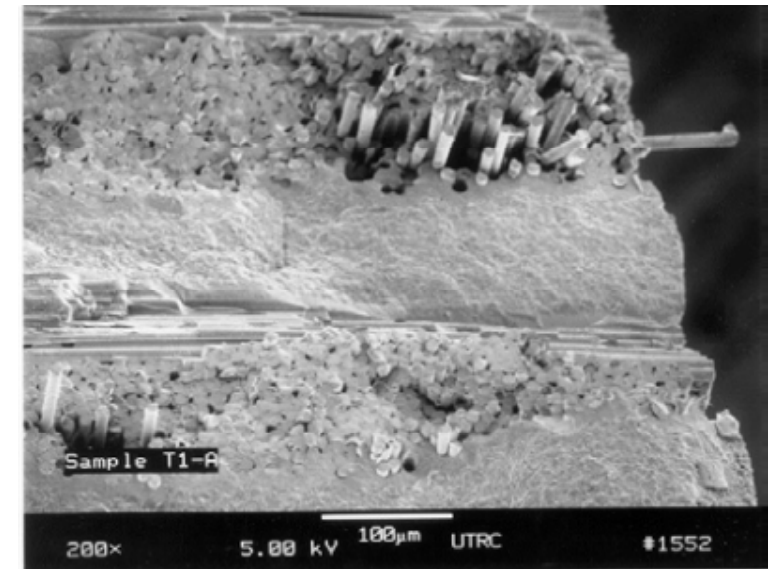

a) Diamond Grinding

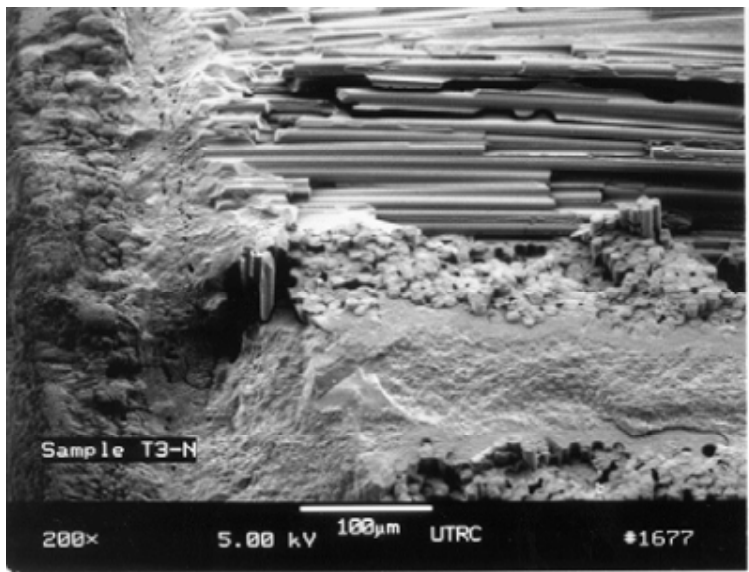

b) Laser Machining Figure 5. SEM images of Fracture Surface for Different Machining Methods

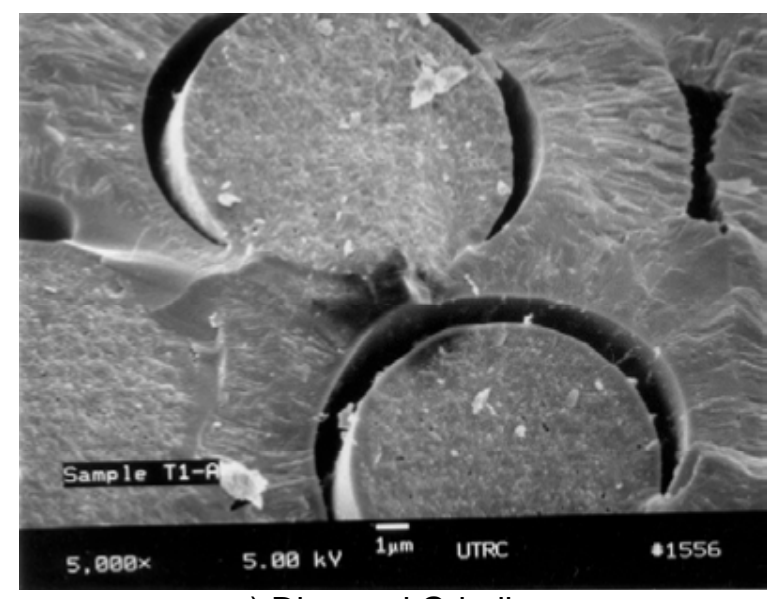

a) Diamond Grinding

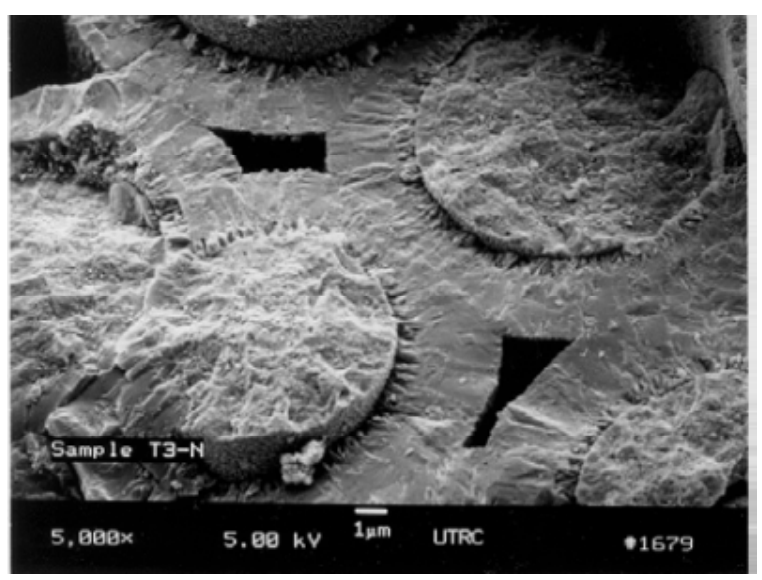

b) Laser Machining

Figure 6. SEM images of Fracture Surface for Different Machining Methods Focused on Interface Region

\section{DISCUSSION}

As noted previously, the machining of CMC materials relied heavily on the machining effort of monolithic ceramics, which are known to be very flaw sensitive. Diamond grinding of CMC samples has been focused on sample mechanical performance and no known issues were raised. In addition, the early focus of CMC insertion has been in areas where machining and machining cost was not a primary focus [11].

This is the first known effort, by the authors, to look at the long term behavior of a class of CMC material in a known aggressive environment with differing machining approaches. It is clear from the work that the laser machining results in a higher strength and strain to failure (see Table I and Figure 4). This can be attributed to lower oxidation degradation as confirmed by SEM images showing that the interface was not attacked during the environmental exposure (Figure 6b). 
The presence of the recast layer from laser machining (See Figure 3) appears to be the main reason for the increased residual capability. The presence of the recast layer inhibits cracks from reaching the surface. This eliminates a prime path for oxidation attack of the weak interface coating. To see if this was the case, microprobe analysis was done near the machined edge of the fully exposed tensile bars to determine if the weak interface was protected. This work is shown in Figure 7. Figure 7 clearly shows that oxygen has progressed to the weak interface, regardless of the machining approach. What is seen in Figure 7 is that the depth of penetration was greatly reduced for the laser machined sample. In addition, the recast layer appears to be an oxygen getter. This suggests that the recast layer aided in the environmental protection of the material.

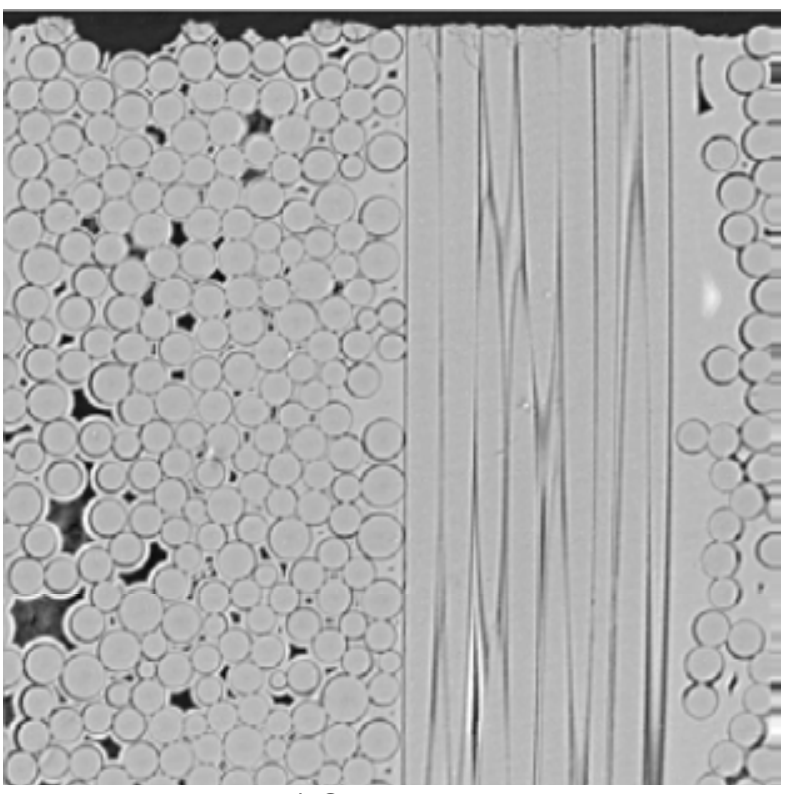

a) SEM Image

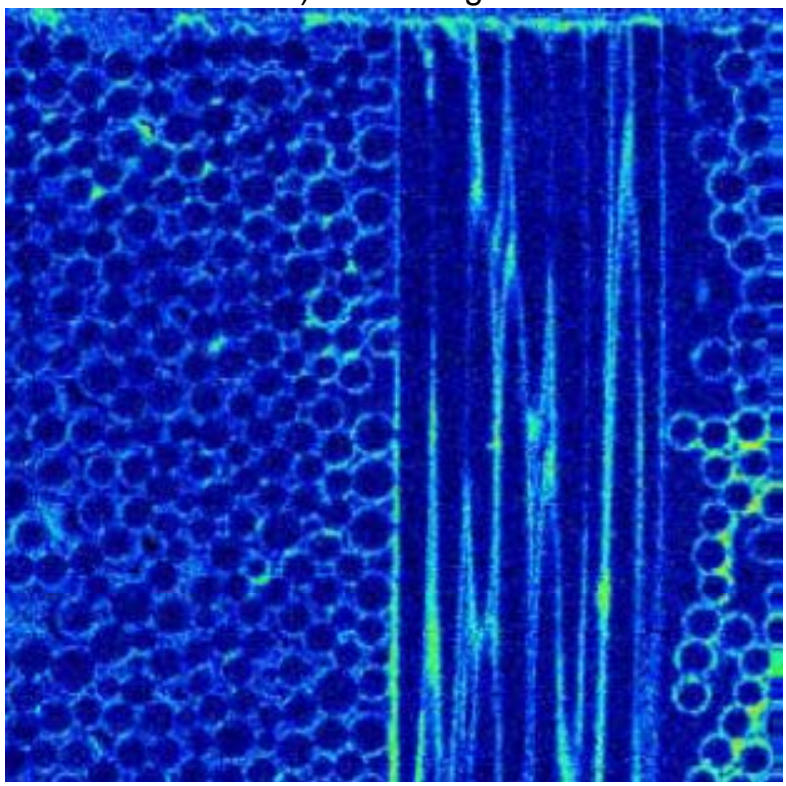

b) Oxygen Map

Diamond Grinding

Figure 7. Microprobe Element Analysis for Oxygen after Exposure

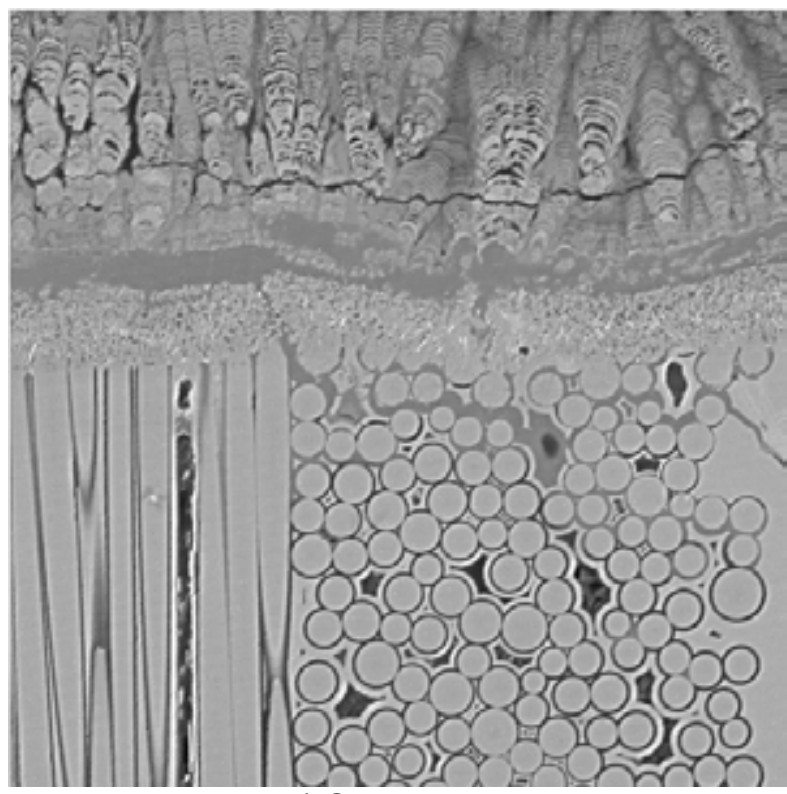

b) SEM Image

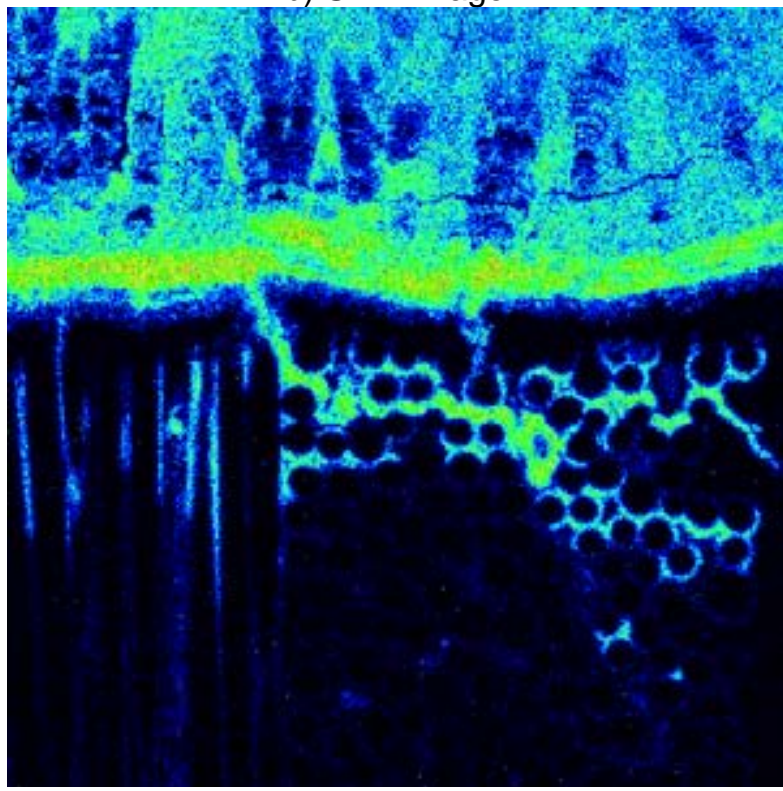

c) Oxygen Map

Laser Machining (two machining cases) 


\section{CONCLUSION}

The work performed has shown a clear differentiation between the two machining process, in regards to the environmental protection of the machined edges. The laser machining resulted in the formation of the recast layer which provides a barrier to oxygen ingress into the material. The clean diamond ground edge did not inhibit the ingress of oxygen. The laser machined specimens had higher residual strength, after environmental exposure, which was exhibited by a lack of attack of the fiber interface coating and oxidation of the recast layer. It was clear from these efforts that laser machining should be considered for the MI SiC/SiC material system.

\section{FUTURE WORK}

Additional work is needed to determine if faster machining rates can be used and how beveled edges could be produced. In cases where tolerances need to be kept, laser machining, followed by diamond grinding, may be an option. This would eliminate the environmental protection documented in this effort. This work also needs to be extended into other CMC systems, to see if laser machining is as effective when a metal phase is not present.

\section{ACKNOWLEDGMENTS}

Work performed under the Enabling Propulsion Materials Program, Contract NAS3-26385, Task A, David Brewer program manager.

\section{REFERENCES}

1. K.K. Chawla (1998), Composite Materials: Science and Engineering, $2^{\text {nd }}$ Ed., Springer, New York.

2. Brewer, D., 1999, “HSR/EPM Combustion Materials Development Program”, Materials Science \& Engineering, 261(1-2), pp. 284-291.

3. Brewer, D., Ojard, G. and Gibler, M., "Ceramic Matrix Composite Combustor Liner Rig Test:, ASME Turbo Expo 2000, Munich, Germany, May 8-11, 2000, ASME Paper 2000GT-670.

4. Verrilli, M. and Ojard, G., "Evaluation of Post-Exposure Properties of SiC/SiC Combustor Liners testing in the RQL Sector Rig”, Ceramic Engineering and Science Proceedings, Volume 23, Issue 3, 2002, p. 551-562.

5. ASTM C1161 "Standard Test Method for Flexural Strength of Advanced Ceramics at Ambient Temperature”, American Society for Testing and Materials, West Conshohocken, PA.

6. Calomino, A., NASA-Glenn Research Center, personal communication.

7. J.A. DiCarlo, H-M. Yun, G.N. Morscher, and R.T. Bhatt, "SiC/SiC Composites for 1200oC and Above" Handbook of Ceramic Composites, Chapter 4; pp. 77-98 (Kluwer Academic; NY, NY: 2005).

8. Ojard, G., Morscher, G., Gowayed, Y., Santhosh, U., Ahmad J., Miller, R. and John, R., "Thermocouple Interactions During Testing of Melt Infiltrated Ceramic Matrix Composites”, Ceramic Engineering and Science Proceedings, pp. 11-20. 2008.

9. Jarmon, D., United Technologies Research Center, unpublished research. 
10. Ojard, G., Gowayed, Y., Morscher, G., Santhosh, U., Ahmad, J., Miller, R. and John, R., "Creep and Fatigue Behavior of MI SiC/SiC Composites at Temperature”, Published in Ceramic Engineering and Science Proceedings, 2009.

11. Kestler, R. and Purdy, M., "SiCf/C For Aircraft Exhaust”, presented at ASM International's 14th Advanced Aerospace Materials and Processes Conference, Dayton, $\mathrm{OH}, 2003$. 